at none of the lower stations gave indications of the ascensional and descensional movements of the atmosphere to which attention is here directed.

We observe from a circular we have before us, signed by the Duke of Richmond and Gordon, President of the Scottish Meteorological Society, that the Society has obtained from Mrs. Cameron Campbell of Monzie, a suitable site for the proposed observatory on the top of Ben Nevis, that the grounds and buildings are to be invested in the Royal Society of Edinburgh, and that the charge and management of the observatory will be in the Council of the Scottish Meteorological Society, in conjunction with two representatives of the Royal Society of Edinburgh, and one representative of the Royal Society of London, the representatives of the former Society being Prof. Tait and Prof. Chrystal, and that of the latter Sir William Thomson.

It is satisfactory to learn that a good beginning has been made towards raising the 5000l. required to establish the observatory, by a number of noblemen and gentlemen, who have intimated handsome subscriptions to the fund. Since, however, a large sum remains yet to be subscribed, we earnestly hope that in the interests of science the remaining balance of the $5000 l$. will soon be subscribed, so that next summer may see the Ben Nevis Observatory an accomplished fact.

\section{NOTES ON THE GEOLOGY OF HONGKONG}

WRITING in I843, Dr. Abel determined the main structure of the island to be of basaltic trap, granite, siliceous and schistose rock. Mr. Kingsmill in 1865, in his excellent papers on the Geology of the Kwangtung Province, was the first to notice the trachytic porphyry of Victoria Peak (1823), the summit of which overlooks the town. 'This trachytic rock has been apparently forced upwards through the granite after the overflowing and partial hardening of the trap on the west side of the island. It was Mr. Kingsmill also who explained the nature and formation of the pseudo-boulders, with which the island is so plentifully covered. Towards the extreme south-east, near Cape d'Aguilar, these pseudoboulders assume very large dimensions, and their weatherbeaten aspect proves that the chemical action of water and plants, which forced them from the parent rock, occurred a long time ago. Indeed the island must have undergone great changes in course of time: the bill beyond Shekko, for instance, must have been originally nearly or quite as high as Victoria Peak, whereas its present elevation is not more than 500 feet. The rapid action of the heavy rains and rich vegetation is nowhere more apparent than in the high hill (directly back of the peak from which the colony takes its name) known as the Hog's Back, or High West. Its eastern slope is literally covered with pseudo-boulders, rendering the ascent from that side not a little dangerous, and in the rainy season large masses of rock are borne down into the valley beneath.

Now that the population of the islınd has increased, amateur geologists and mineralogists have become tolerably plentiful, and frequent excursions are made, hammer in hand, to the less known and wilder portions of the island. In this manner traces have been found of not a few minerals and several interesting rocks. Silver has been observed in small quantities, also galena, lead, and iron pyrites; slate near Aberdeen, syenite and dolorite on a cliff overlooking that one-time piratical rendezvous, Saiwan, feldspar and grey mica abundant.

One of the most interesting finds is that of molybdenite, near the village of Sau-ki-van. Molybdenite, molybdenum glance $\mathrm{MoS}_{2}$, was not known hitherto to be among the mineral products of China. Germany, Sweden, and Cornwales are the chief localities for this rare mineral, and it has been found in several parts of the United
States. The South China specimens show all the wellknown characteristics of European molybdenite-colour, lead-grey, streak the same; thin foliated hexagonal plates, closely resembling graphite ; flexible, non-elastic laminæ, $H_{.}=\mathrm{I} \cdot 2, \mathrm{G} .4$, 5. A local chemist corroborated the determination by analysis, and found the composition to be-

$$
\begin{array}{llllllll}
\text { Sulphur } \ldots & \ldots & \ldots & \ldots & \ldots & \ldots & =40^{\circ} 0 \\
\text { Molybdenum } & \ldots & \ldots & \ldots & \ldots & \ldots & =\underline{60^{\circ} 0} \\
\text { Molybdenum sulphide } & \ldots & \ldots & \ldots & =100^{\circ} 0
\end{array}
$$

It will be seen from this analysis that there is a slight decrease in the quantity of sulphur, compared with European molybdenite. Dana gives the composition of American molybdenum sulphide as follows :-

$$
\begin{aligned}
& \begin{array}{llllllll}
\text { Sulphur } & \ldots & \ldots & \ldots & \ldots & \ldots & \ldots & =4 \mathrm{r}^{\circ} \mathrm{O}
\end{array} \\
& \begin{array}{llllll}
\text { Molybdenum } & \ldots & \ldots & \ldots & \ldots & \ldots
\end{array} \\
& 100 \%
\end{aligned}
$$

The mineral was found in small lumps imbedded in the granite.

Hongkong, November

\section{TRANSIT OF VENUS, I882-BRITISH EXPEDITIONS}

$A N$ operation which requires for its success the collection of nearly simultaneous astronomical observations over widely separated portions of the earth's surface must always be liable to great risks of failure. These risks may be diminished by a careful selection of stations, and an increase in their number; but they can never be entirely removed.

The telegrams already received show, however, that the British expeditions have been most fortunate; and the success of the work is now assured.

This is not the proper place for a technical discussion of the different methods which may be adopted for the determination of the sun's distance from a discussion of observations of Venus in transit; but it is desirable that some facts should be stated which may enable the reader to form some conception of the strength of the method which has been relied upon in the organisation of the British expeditions, and the probable accuracy of the sun's distance which may be deducible from a careful discussion of the observations which have been collected.

On December 6, 2h. 2om. G.M.T., the sun was distant from the earth about $90,620,000$ miles, whilst at the same time Venus was distant only about $24,330,000$ miles. The ratio of these two numbers is very accurately known, but the expression of either of these two distances in terms of any unit of length which is directly known to us, as a mile, is a point of great difficulty on account of the small dimensions of our earth, of which the dianseter is only about 7912 miles, in comparison with such distances as those of Venus and the sun.

The greatest possible displacement of Venus, as seen projected on the sun's disc from any two places on the earth's surface is only about a twenty-ninth part of the solar diameter. It is from such displacements that the relation between the distances of Venus and the sun and the separation of the observers, which is known in miles, is established; but the maximum displacement is never practically available.

These displacements may be measured in many different ways: we can take photographs of the sun's disc at the different stations, and afterwards measure from the photographs the distances between the centres of the planet and the sun, as seen at the different stations; or the distances between the centres may be directly measured with a heliometer or any equivalent instrument; or we may avoid the difficulties and errors 
which arise from the use of all such measuring instruments, use the sun itself as our circle of reference, and infer the displacements by observing the differences in time at which Venus is apparently in contact with the sun's limb, as seen from the opposing stations. The last method is that upon which reliance has been chiefly placed in the organisation of the British expedition. For the success of this method, we have to place observers at two sets of opposed stations, at one of which Venus is thrown, from the effects of perspective, towards the centre of the sun at ingress, whilst at the other set of stations Venus is thrown from the effects of perspective from the centre. The former stations are called stations of accelerated ingress, the latter those of retarded ingress.

The stations of the egress observations are chosen from similar considerations, and divide themselves into stations of accelerated egress and retarded egress. In the selection of stations, the most important points are, that the effects of the apparent displacements on the difference in the times of contact should be considerable, that the climatic conditions should be generally favourable, and that the altitude of the sun should be sufficient to render a good observation possible.

The principal stations selected for the British observations of accelerated ingress were Madagascar and the Cape; but it is hoped that good observations may have been secured by Mr. Meldrum, the director of the observatory at Mauritius, although the altitude of the sun is very low for that station at the time of contact. The observers at Madagascar were the Rev. S. J. Perry and the Rev. W. Sidgreaves, with Mr. Carlisle as an assistant. The instruments provided were excellent 6 -inch equatorials. The expedition was placed under the care of Commander Aldrich, of H.M.S. Fawn, with instructions to establish the observers near the coast on the southwestern part of the island. A telegram has been received, stating that the Faren had returned to Natal, and that the observations had been perfectly successful.

The observations at the Cape have also been successful. At the Observatory there, Mr. Gill reports that seven observations of contact were made. The instruments available at this station were a fine 7 -inch telescope by Merz, which belongs to the Observatory, and a new 6-inch equatorial by Grubb, sent out by the Committee for the observation of the transit, and a good Dollond, which was used at the last transit, with an aperture of nearly four inches, and Mr. Gill's heliometer, The goodness of the contact observations with the latter instrument may be open to doubt, from the construction of the instrument with a livided object-glass. Three of the contacts must, I fear, have been made with inferior instruments, but at least three good observations of contacts have been made at this station alone.

Mr. Marth, who is in charge of the station at Montagu Road, on the railway between Cape Town and Beaufort West, reports that two good observations of contact have been secured. The observers at this station were $\mathrm{Mr}$. Marth and Mr. C. M. Stevens, with Corporal Thornton as assistant. The instruments provided were a 6 -inch equatorial by Grubb and the fine Dallmeyer instrument which was kindly lent by Dr. Warren de la Rue for the observation of the transit.

At Aberdeen Road, Mr. Finlay, B.A., First Assistant at the Cape Observatory, and Mr. Pett, Third Assistant, were the observers. The instruments were 6 -inch equatorials by Simms, provided by the Committee; a marine artilleryman, Gunner Shean, was sent out from England with the instruments, and was attached to the party as an assistant. The observations have been perfectly successful, and the definition is reported to have been fine.

$\mathrm{Mr}$. Neison has also observed the contacts at Durban, Natal, with a fine equatorial provided by the liberality of the colonists for the observations. Therefore we have at least ten first-rate observations of the internal contact at the phase accelerated ingress made upon one uniform plan and with instruments of the same class.

The longitudes of all the Cape stations have been directly connected with that of the Cape Observatory by telegraph, and the longitude of that station has recently been connected by telegraphic determination with Greenwich.

The Greenwich times of the phase of accelerated ingress range from about $2 \mathrm{~h}$. I Im. os. for Madagascar to 2h. I2m. 8s. for the Cape Observatory. The Greenwich mean time for the general body of observations known to have been secured would not differ greatly from $2 \mathrm{~h}$. IIm. $48 \mathrm{~s}$.

But the observations made of this phase would have been perfectly useless unless observations for comparison with them had been made at stations of retarded ingress.

The stations selected for the observation of retarded ingress were Jamaica, Barbadoes, and Bermuda. But the Canadian Government also provided three 6-inch telescopes; and one of their observers, Lieut. Gordon, Director of the Observatory at Toronto, came over to England to secure the necessary additions to the instrumental means, and to Oxford to make himself acquainted with the arrangements of the other British stations. It is to be feared that this spirited conduct on the part of the Canadian Government has not been followed by the success which could have been wished; but no official reports have yet been received from the Canadian stations.

The phase of retarded ingress has been successfully observed by all the observers sent out in the British expeditions, and the observations, from the telegrams received, appear to have been perfectly satisfactory.

The observers at Jamaica were Dr. Copeland and Capt. Mackinlay, R.A. Mr. Hall was to have observed the contact at another part of the island away from telegraphic communication, and he has not yet reported.

The observers at Bermuda were Mr. Plummer, Lieut. Neate, R.N., and Capt. Washington, R.E.

The observers at Barbadoes were $\mathrm{Mr}$. Talmage and Lieut. Thomson, R.A.

We have therefore, at these stations alone, seven good observations of retarded ingress.

The Greenwich times of the phase of retarded ingress range from about $2 \mathrm{~h} .22 \mathrm{~m}$. $35 \mathrm{~s}$. at Barbadoes, to $2 \mathrm{~h} .24 \mathrm{~m}$. $25 \mathrm{~s}$. at Bermuda. The Green wich mean time for all the observations will not differ greatly from $2 \mathrm{~h} .23 \mathrm{~m}$. 33s., and the available difference between the opposed stations of accelerated and retarded ingress will therefore be about 700 s., and an error of five seconds in the determination of the difference of the observers would not give rise to an error of 700,000 miles in the determination of the sun's distance, because 5 seconds is only the r 4 oth part of the available interval. But even if the separate results at a station should occasionally disagree, Io seconds of time inter se there is no reason whatever why the mean difference in time between the opposed stations derived from seven good contacts at one end, and ten at the other, should have an error of three seconds of time. So that from the British observations of ingress alone it should be possible to estimate the sun's distance within 300,000 miles.

The stations at Bermuda, Jamaica, and Barbadoes, which served for retarded ingress, are also available for accelerated egress.

The egress observations at Jamaica and Barbadoes are reported as satisfactory. Those at Bermuda were apparently only picked up through clouds. It is possible, therefore, that the Bermuda observations may not be available, on this account, for combination with the other observations; but with the Jamaica and Barbadoes observations alone we have at least four good contacts. 
These accelerated egress contacts were made, roughly, about $7 \mathrm{~h} .47 \mathrm{~m}$. Greenwich mean time.

Corresponding to these, we have for the phase retarded egress the New Zealand observations and the observations by Ellery and his staff at Melbourne. The observers at New Zealand were Lieut.-Col. Tupman, R.M.A., and Lieut. Coke. The internal contacts must have been made about 8 h. om. 3os. G.M.T.

Observations of this phase which were secured by Mr. Ellery and his assistants at Melbourne must have been made about $8 \mathrm{~h}$. Im. 30s. G.M.T.

The failure of the Brisbane observations through clouds and the partial failure at least of the Bermuda observations at egress have considerably weakened the weight of the determination of the sun's distance from the egress observations. But the observations secured with the large available difference of time of about 840s. should most certainly give a determination of the sun's distance from the egress observations alone with an error less than 500,000 miles.

Besides the above observations, Capt. Wharton, H.M.S. Sylvia, has been provided with two good telescopes; and, if the weather has been favourable, will have secured observations both of the ingress and egress, having established himself at some station on the South American continent, not far from the Falkland Islands.

The Greenwich mean times of internal contact at Capt. Wharton's station may be taken at about $2 \mathrm{~h}$. $15 \mathrm{~m}$. at ingress, and $7 \mathrm{~h} .52 \mathrm{~m}$. at egress. The computed times for the contacts at Capt. Wharton's station would be but little affected by any error in the assumed mean distance of the sun, but they are influenced as much as the other stations by any error in the assumed distance between the centres of Venus and the sun at which the contacts take place. Observations, therefore, at such a station are of importance as a check upon the results obtained from the comparison of results from stations of greatly accelerated and retarded phase.

The longitudes of stations in Jamaica and Barbadoes have already been connected with Greenwich through Washington by the American observers by means of telegraphy. Lieut. Neate has determined the longitude of Bermuda through Washington, by the conveyance of chronometers between Bermuda and New York, where Washington time is available. Arrangements have been definitely made for Lieut. Darwin, R.E., to connect Port Darwin with Singapore, and thus the telegraphic longitude of the Australian and New Zealand stations, which have already been connected together, will be determined.

The longitude of the Madagascar station has been determined by the conveyance of chronometers between Durban, in Natal, and Madagascar, the sea rate of the chronometers being ascertained by their rates during the voyage between Durban and Cape Town.

It will be seen, therefore, that there will be no difficulty in the discussion of the observations from the want of accurate knowledge of the position of the observing stations.

The observations of the British Expeditions have been made by observers of skill, with excellent instruments, under approximately similar conditions of illumination and with sufficient optical powers. 'The observers have all been trained to observe the same kind of contact, and that one of so distinctive a character that no dou'sts about the time record which refers to the kind of contact required for comparison with those made at other stations should be possible. This point is one of the utmost importance. In all attempts to determine the sun's distance from these contact observations we have to assume that the "contacts observed" took place with the same angular separation of the centres of Venus and the sun as seen from the observers' position on the earth's surface. There is no reason whatever why this assumption should be true unless the "contacts observed" are contacts of the same class. There is an interval of more than $20 \mathrm{~m}$. between the "external contact" at a station and the "internal contact" at the same station. If, therefore, any one should combine the time of external contact at one station with the time of internal contact at another station, without allowing for the motion of the earth and Venus, in the interval of about twenty minutes he would obtain a startling but very erroneous result for the sun's distance. The error thus indicated would, however, differ nothing in kind, but only in degree from those which have, to some extent, unfortunately, brought this method of contact into doubt.

The success of the British observations, particularly at ingress, has, however, been so complete, that the method of contact will now have a fair trial.

I await the result with perfect confidence. Neither the method of contact nor any other known method can, with our present instrumental means, settle the sun's distance to a hundred thousand miles. But the extreme range of possible uncertainty, as shown by the difference between the results obtained from Mr. Gill's heliometer measures of Mars east and west of the meridian at the opposition of 1877 , and those obtained from the differences in North Polar distances between Mars and stars on the meridian as observed at our principal northern and southern observatories at the oppositions of 1862 and 1877 , is about $\mathrm{r}, 700,000$ miles. All our other recent determinations, which have stood the test of examination, fall within these limits, and do not generally differ much from. $92,000,000$ miles. The contact observations of the British expedition will, I feel confident, fix the true distance, without any greater error than 300,000 miles, and should settle the question whether either of the extreme values mentioned can be the true distance, or whether their mean is not much nearer the truth than either of them.

E. J. STONE

We have received the following additional communications on the transit:-

THE observation of the transit of Venus here to-day was attended with a remarkable, and I think hitherto unnoticed phenomenon.

When the planet had entered nearly one-half its diameter on the solar disc, its contour was barely traceable outside by the faintly luminous line of light noticed by previous observers. But in addition to this a spot of light extending through nearly $30^{\circ}$ of the planet's circumference, and from its periphery inzuards for about onefourth of the radius was distinctly seen. The brightness appeared greatest at the outside, and faded toward the centre. This appearance was noted by me through the great equatorial, by the aid of a polarising eye-piece, and a magnifying power of 244 . The position-angle of the bright spot was approximately $178^{\circ}$, as estimated by me (for, owing to the fact that the polarising eye-piece has no position-circle, only an estimate was possible).

At the same time an assistant (Mr. J. E. Keeler), observing with a telescope of only $2 \frac{1}{4}$ inches aperture and a power of 70 , was able to see the same bright spot quite independently, and estimated its position-angle at $168^{\circ}$. The position-angle of the planet itself on the solar disc was approximately $147^{\circ}$. The bright spot was therefore distinctly on one side of a line passing through the centres of the sun and Venus.

The observation was repeated at intervals through passing clouds for seven or eight minutes, and whatever may be its interpretatiơn, of the fact of observation there can be no question.

There would seem to be no analogy between this very peculiarly disposed and definite bright spot upon the planet's edge, and the small central spots described by 
some (and whose existence is denied by others) which have been seen on Mercury and Venus in transit, when they have completely passed on to the disc.

S. P. LANGLEY,

Director of the Observatory

Allegheny Observatory, Allegheny, Pennsylvania, December 6

THE transit was observed here in a cloudless sky up to sunset, but the low position and great atmospheric disturbance rendered measurements and observations of contact unreliable.

When Venus was half in on the sun, I distinctly perceived a fine curved thread of subdued light on the south-eastern edge outside the sun, and not reaching to the latter, nor extending far on any side. With threefourths on, the thread of light reached round the remaining fourth outside, and completed the periphery. The segment of light disjoined, as when first observed, would seem to indicate a superior refractive power of the planet's atmosphere in the locality at the time.

A short time before complete ingress, the solar cusps appeared to project out from the disc in double concave forms to join the aureole. The aureole disappeared after complete ingress, but the outer portion of the planet seemed much less dark than the central, which was perfectly black within a dark brown ring of from $5^{\prime \prime}$ to $1 \mathrm{O}^{\prime \prime}$ in breadth. I saw no trace of the black drop or ligament, and, indeed, I should imagine that the aureole crossing the position of the ligament would prevent its appearance. I found nothing like a satellite. I thought the micrometer showed a diameter of the planet rather greater from east to west than from north to south, but the boiling of the limbs prevented any measures that could be depended on. I remarked no distortion of the planet as recorded by observers of the previous transit.

Millbrook, Tuam, December 8 JOHN BIRMINGHAM

IN a published letter, dated "Palermo, December I3, 1882," Signor Cacciatore, Director of the Royal Observatory there, writes as follows:-"The observations of the transit of Venus, effected at our Observatory, present results, both as regards the direct observations and the spectroscopic, to which the attention of astronomers and physicists may fairly be invited. Prof. Ricco, with the spectroscope, when the planet was on the sun's disc, and her image entered upon and left the slit, observed near the spectral line $B$ of the more refrangible side, a very weak absorption band, and also near the line $C$ he saw traces of obscuration, but much more weak and uncertain. The same phenomenon, $P$. Tacchini writes me, was observed by him at Rome. Moreover, my direct observations yielded an indication of the ingress of the atmosphere of Venus upon the sun, as, from those of Prof. Millosevich in Rome, this indication was obtained on the external portion of the planet. The agreement of such observations made in different places is of no little importance for determination of the existence and the constitution of the atmosphere of Venus."

\section{NOTES}

M. Bertrand, perpetual secretary of the Paris Academy of Sciences, intimates that the French Government is anxious to collect any information relating to Fermat, whose statue will be unveiled very shortly at Toulnuse. Those who posiess any documents relating to Fermat are requested to communicate with the secretary of the Institute.

THE Johns Hopkins University Circulars contain a great amount of important scientific, as well as other information, concerning the work of that institution, which is rapidly developing into one of the most comprehensive and efficient institutions for research and education anywhere. In the number for November, for example, we have notes on the papers read by members of the University at their various societies as well as elsewhere, in mathematice, physics, philology, biology, \&c., synopses of recent American scientific journals (mostly issued from the University), besides abstracts of lectures, critical notes on various subjects, and much other information. From the seventh Annual Report moreover, it is evident that the University has taken a strong hold on the American people, and that both in the spirit and the letter it is amply fulfilling the intentions of the founder. The list of the academical staff alone, professors, associates, lecturers, instructors and assistants, fills three pages, while the account of work in the various departments shows that research has become a part of the everyday life of the institution.

Prof. Tyndall will on Thursday next (December 28), at the Royal Institution, at three o'clock, give the first of a course of six lectures (adapted to a juvenile auditory) on Light and the Eye.

THE death is announced of Dr. Theod. Lud. Wilh. von Bischoff, formerly Professor of Anatomy and Physiology at Munich University, as well as keeper of the Anatomical Institute in that city. He died on December 5 last, aged seventy-five.

ON December I the Agricultural Museum of Berlin was opened to the public. The curator, Herr Settegast, has arranged the zootechnical division in a commendable manner. Numerous paintings and sketches illustrate German domestic animals in their agricultural aspect. In the zoological division there are a number of interesting skeletons and skulls, amongst them a human skull from the shell-tombs at Santos (Brazil).

THE French official journal publishes a report on oyster culture, which is in favour of the Portuguese oyster. It appears that 100 grammes of the flesh of this mollusc contains about 1-1oth gramme of iodine, bromine, and chlorine, just twice as much as the common oyster.

Messrs. Foster and Martin, of Melbourne, have sent us a graceful photograph of the comet, about which we have had so much correspondence. The photograph was taken with a 3 -inch euryscope of 24 inch focus on an ordinary camera, not equatorially mounted, which doubtlessly accounts for the elongation of the nucleus. The photograph is creditable to Messrs. Foster and Martin, though it is not the first time a comet has been photographed; more than a year ago we reproduced the photograph of the comet of the period, taken by Dr. Janssen of Paris.

Actn Mathematica is the name of a new mathematical journal which will appear this month, simultaneously published in Stockholm, Berlin, and Paris. The editor in chief is Prof. J. Mittag.Leffler, of Stockholm, and the publication has been promised the support of the most distinguished mathematicians of Scandinavia, Germany, and France.

LAST week the Crystal Palace Company inaugurated an Exhibition of Electricity and Gas which give; even greater promise of succe-s than that in which electricity was the sole object of attraction. Gas at present occupies the largest display. Exhibitors demonstrate the utilisation of gas, and there are many practical illustrations going on. The South Nave contains a great collection of all the best systems of improved gas lighting, Sugg's stand being distinguished by an immense standard lamp of 1000 candle power and a series of suspended lanterns of tasteful pattern of 600 -candle power. There are similar great gas lights by Bray, Siemens, and others, which are submitted as competitors against the electric arc lights. In the North Nave there are numerous stands of electric apparatus and material. 